\title{
Evaluation of Arthroscopic ACL Reconstruction by 3 different Techniques
}

\author{
Amit Ahluwalia ${ }^{1}$, Atul Mishra ${ }^{2}$, Rajul Rastogi ${ }^{3 *}$ and Pallavi Ahluwalia ${ }^{4}$ \\ ${ }^{1}$ Senior Consultant Orthopedics, Moradabad, UP, India \\ ${ }^{2}$ Senior Consultant Orthopedics, Fortis Hospital, Noida, UP, India \\ ${ }^{3}$ Associate Professor Department of Radiodiagnosis, Teerthanker Mahaveer Medical College \& Research Center, Moradabad, India \\ ${ }^{4}$ Professor Department of Anesthesia, Teerthanker Mahaveer Medical College \& Research Center, Moradabad, India
}

Submission: April 30, 2018; Published: May 31, 2018

*Corresponding author: Rajul Rastogi, Associate Professor, Department of Radiodiagnosis, Teerthanker Mahaveer Medical College \& Research Center, Moradabad, Uttar Pradesh, India, Email: rajulrst@yahoo.co.in

\begin{abstract}
In the present era of increased human activity and trauma, more and more incidences of knee injuries especially anterior cruciate ligament are coming for medical work-up. With the recent development in imaging and arthroscopic techniques many approaches have evolved for management of ACL tears. The present article evaluates the outcome of ACL reconstruction by three different arthroscopic techniques.

Keywords: Arthroscopy; Reconstruction; Anterior cruciate ligament
\end{abstract}

\section{Introduction}

The goal of arthroscopic anterior cruciate ligament (ACL) reconstruction is to restore joint function by restoring normal knee kinematics. Biomechanical studies have demonstrated that single bundle ACL reconstruction is insufficient for controlling rotation in extension. Double bundle ACL reconstruction has been shown to provide more improvement in knee stability theoretically because it more closely mimics the anatomic structure of ACL.

\section{Aims and Objectives}

To analyze the clinical outcome of arthroscopic anterior cruciate ligament (ACL) reconstruction over a period of 1 year using 3 different surgical techniques using hamstring autograft.

\section{Material and Methods}

The medical records of 58 consecutive patients who underwent arthroscopic ACL reconstruction were retrospectively evaluated. The following inclusion criteria were used:

i. Presence of unilateral isolated monoligamentous injury

ii. No history of surgery on the contralateral knee or extremity

iii. No history of surgery on the ipsilateral extremity.

Different surgical techniques used were: a. Hamstrings (semitendinosus and gracilis (STG) combined) by Double-Bundle anatomical reconstruction (DB) [1,2].

b. Quadrupled Single-Bundle reconstruction (SB).

c. Over the top with Lateral Plasty (OTLP (combined intra and extra-articular tenodesis technique)).

\section{Observations}

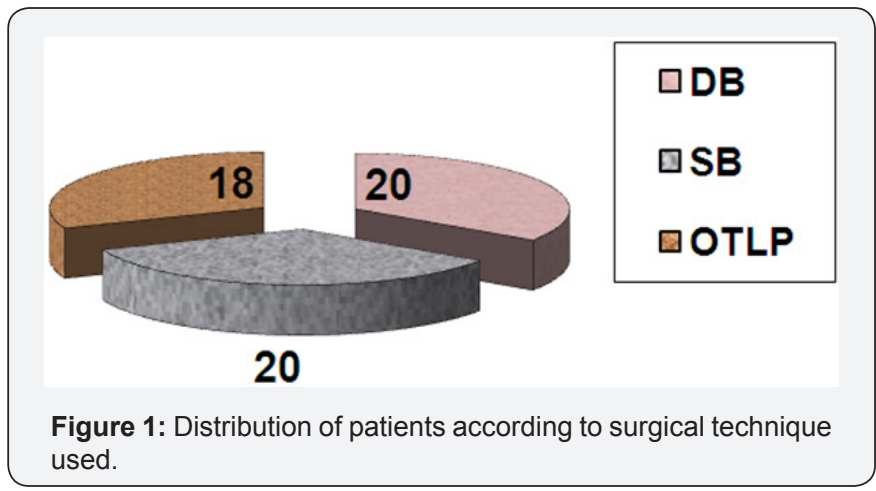

Figure 1 shows the distribution of patients according to surgical technique used. The type of reconstruction selected was dictated by the need to obtain a sufficient length of hamstring graft and affordability of the patient for the implants OTLP (Table 1). 


\section{Orthopedics and Rheumatology Open Access Journal (OROAJ)}

Table 1: Demographic data of patients.

\begin{tabular}{|c|c|c|c|}
\hline Surgical Group & OTLP & SB & DB \\
\hline No of patients & 18 & 20 & 20 \\
\hline Mean age in yrs & 24.6 & 25.6 & 24.7 \\
\hline Male/Female ratio & $15 / 3$ & $15 / 5$ & $17 / 3$ \\
\hline $\begin{array}{c}\text { Mean time to surgery } \\
\text { (months) }\end{array}$ & 2.7 & 2.6 & 2.9 \\
\hline
\end{tabular}

Surgical Technique: Over the Top with Lateral Plasty (Figures 2-4)

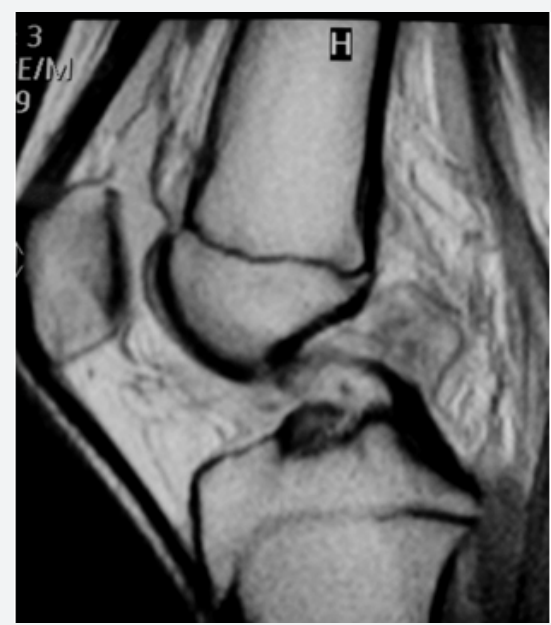

Figure 2: Preoperative sagittal T2W MRI image shows complete ACL tear with avulsion fracture of anterior tibial spine.

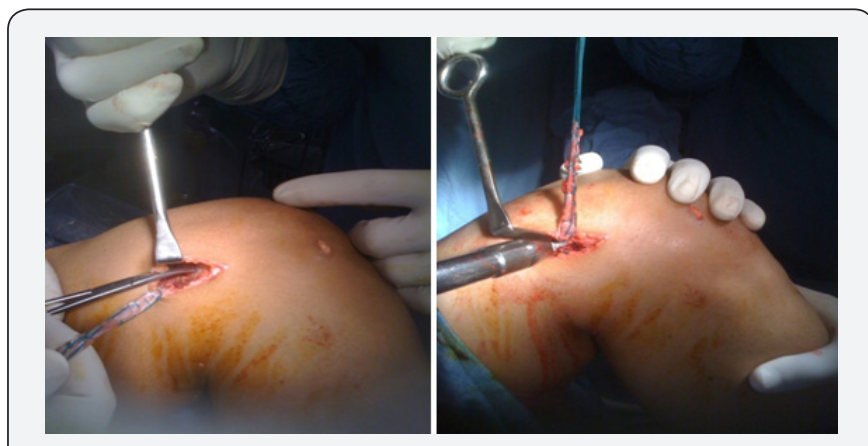

Figure 3: Intraoperative images.

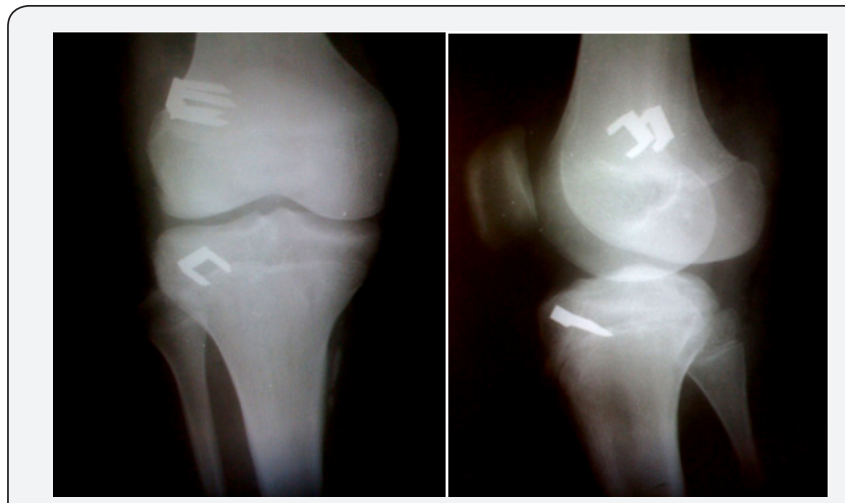

Figure 4: Postoperative radiography in AP and Lateral views. i. STG autograft was harvested using an open type tendon stripper. The insertion of STG over tibia was however preserved.

ii. Tibial tunnel was drilled using $6 \mathrm{~mm}$ diameter cannulated reamer and was further dilated using a $7 \mathrm{~mm}$ dilator.

iii. Over the top femoral position was prepared.

iv. The STG auto graft was negotiated through the tibial tunnel and routed over the top of the lateral femoral condyle.

v. Fixation on the lateral femoral cortex was done by two $8 \mathrm{~mm}$ ligament staples.

vi. Prior to fixation, manual tensioning of the graft was done by constantly pulling the graft and subjecting the knee through a full range of motion 10 times.

vii. Fixation was done keeping the knee in $90^{\circ}$ flexed positions while maintaining a posterior push on the tibia and externally rotating the tibia by $10^{\circ}[3]$.

viii. The remaining graft was negotiated distally beneath the fascia lata and fixed on Gerdy's tubercle with one ligament staple keeping the knee in the same position as above.

ix. Notch plasty was not done.

Surgical Technique: Single Bundle Reconstruction (Figures 5-8)
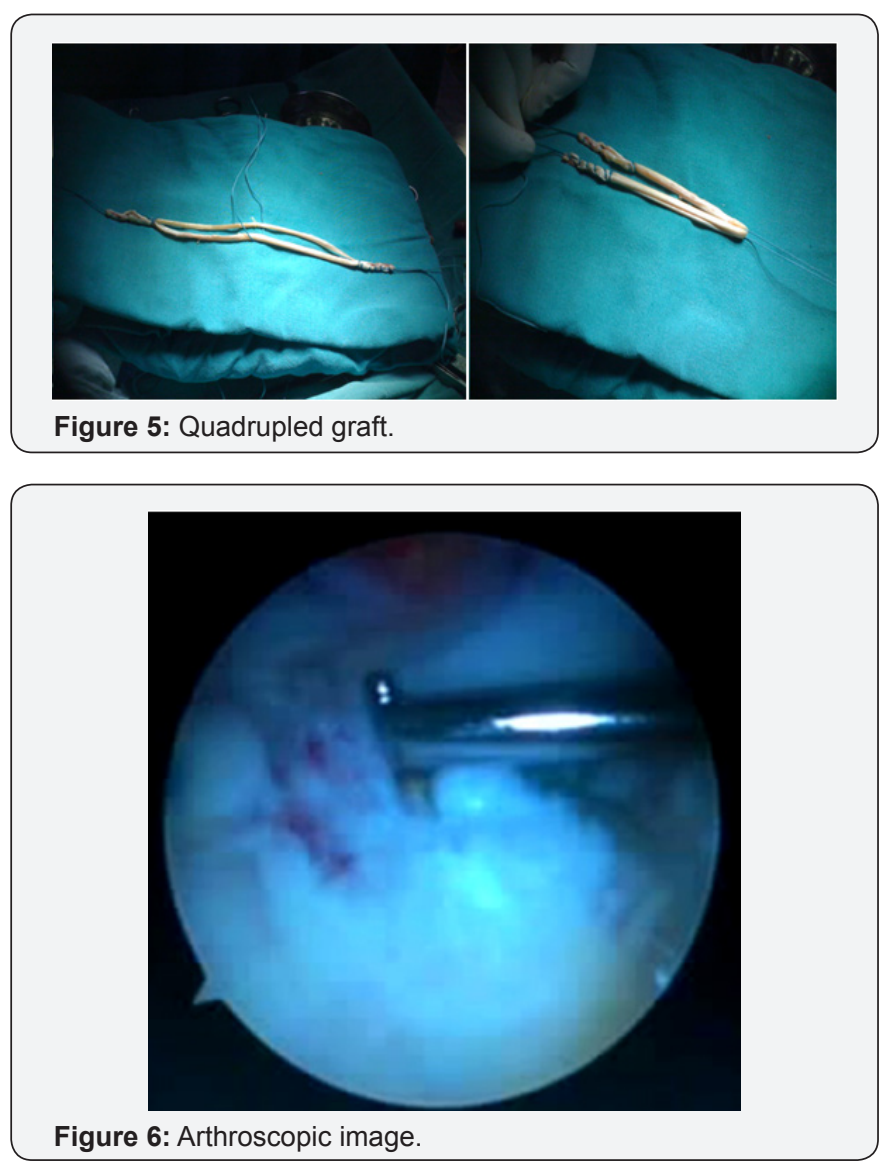


\section{Orthopedics and Rheumatology Open Access Journal (OROAJ)}
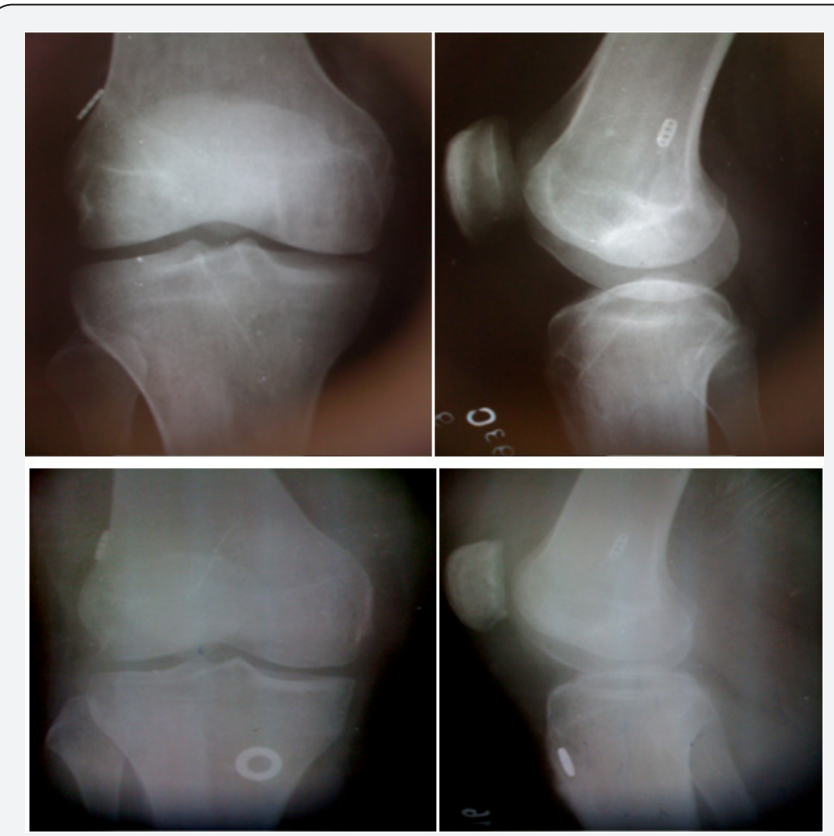

Figure 7: Postoperative radiographs in AP and Lateral views.
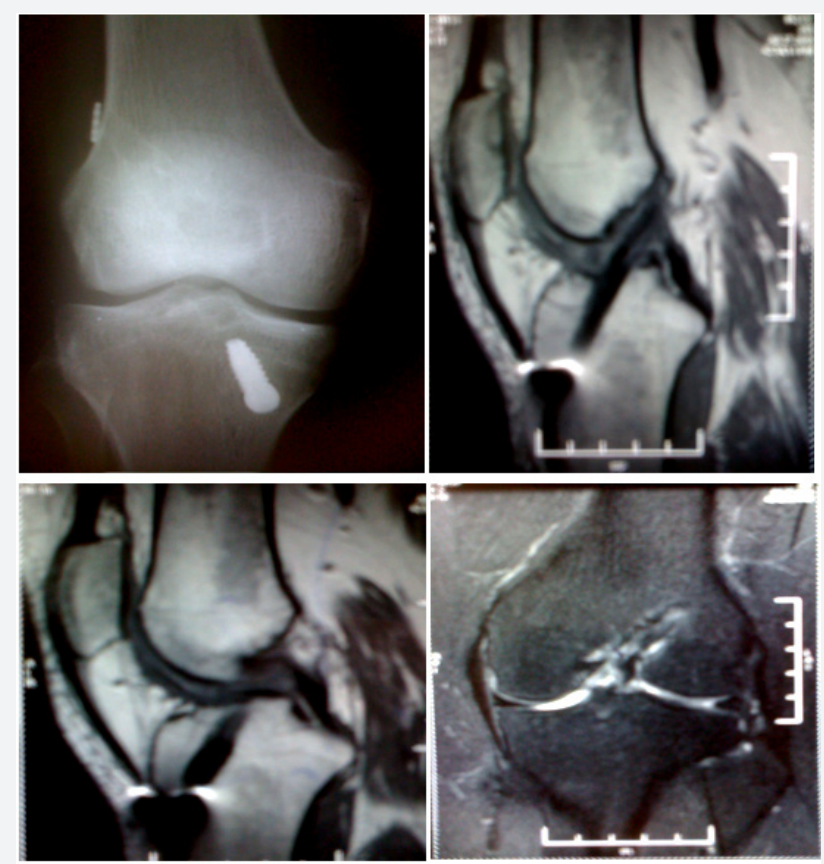

Figure 8: Postoperative radiograph in AP view and sagittal T2W, T1W \& coronal STIR MRI images.

\section{Graft preparation}

a. STG was harvested and the insertion was sacrificed.

b. Gracilis \& ST were stitched together and quadrupled.

c. A tibial tunnel was drilled up to 7-8mm depending on the diameter of quadrupled graft.

d. A femoral guide pin was positioned at 10.30 o'clock on the right knee and 1.30 o'clock on the left knee with 90- $110^{\circ}$ flexion at the knee, using an appropriate offset device inserted through the AM portal [4].

e. An appropriate size tunnel was prepared.

f. Manual tensioning of the graft was done by constantly pulling the graft and subjecting the knee through a full range of motion 10 times.

g. Femoral fixation was done using endobutton (CL, Mersilene tape)

h. Tibial fixation was done keeping the knee in $30^{\circ}$ flexion with metal/ bio interference screw.

Surgical Technique: Double Bundle Reconstruction (Figures 9-11)

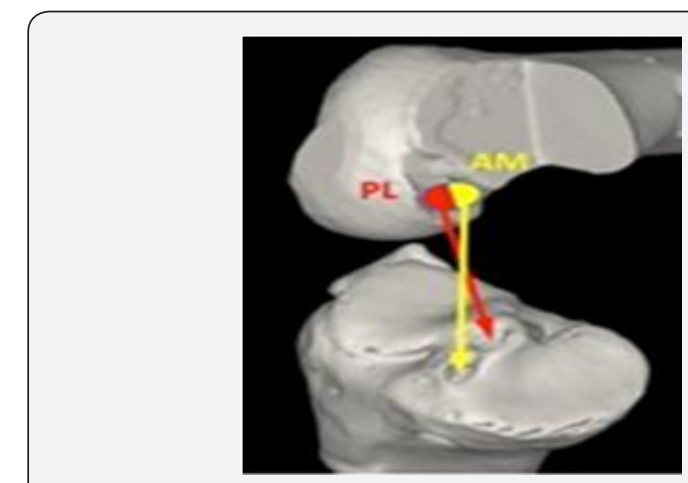

Figure 9: 3DCT image showing attachment of $A C L$ bundles.

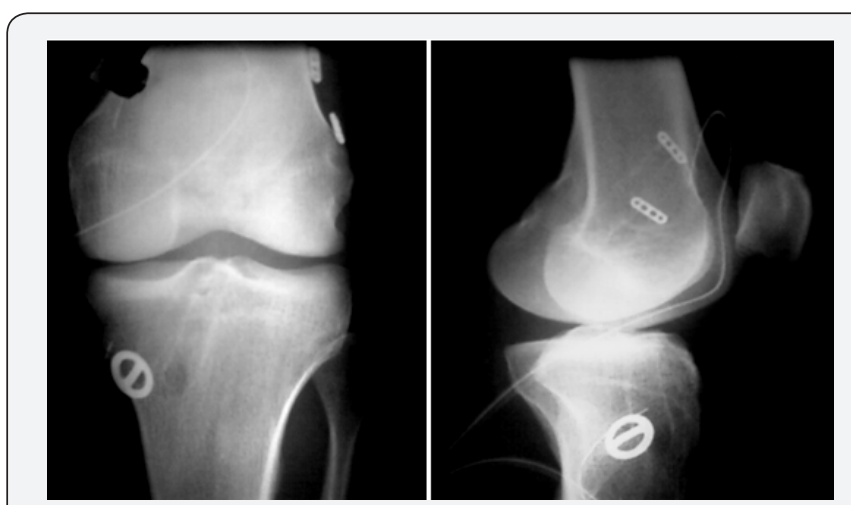

Figure 10: Postoperative radiography in AP and Lateral views.

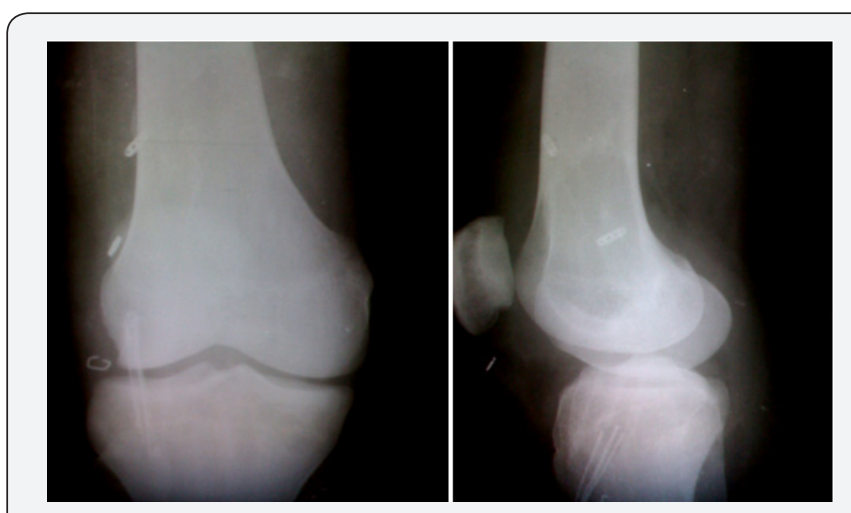

Figure 11: Follow up radiographs in AP \& Lateral views. 


\section{Graft preparation}

Semitendinosus and Gracilis tendons were separately prepared so as to obtain a minimum graft diameter of $7 \mathrm{~mm}$ for anteromedial (AM) bundle and $5-6 \mathrm{~mm}$ for posterolateral (PL) bundle.

\section{Femoral tunnel preparation}

For AM femoral tunnel, a $4 \mathrm{~mm}$ over the top guide was inserted through the AM portal keeping the knee in about $100^{\circ}$ of flexion and placed on the proximal cortex of the intercondylar notch at about 11 o'clock for the right knee and 1 o'clock for the left knee.

\section{PL femoral tunnel preparation}

The $4 \mathrm{~mm}$ offset guide hook was placed in the AM femoral tunnel and the knee was flexed further by $5-10^{\circ}$ to get adequate divergence of the two tunnels.

\section{PL tunnel entry point identification}

i. The point lies roughly at the same level in horizontal plane in relation to $\mathrm{AM}$ tunnel in $90^{\circ}$ knee flexion.

ii. The center of the PL bundle footprint is approximately located at the crossing point of the long axis line of the ACL attachment and a vertical line drawn through the contact point between the femoral condyle and tibial plateau at $90^{\circ}$ of knee flexion.

iii. The socket was placed at 9 o'clock position for the right knee and 3 o'clock position for the left knee.

iv. The position of the guide wire was rechecked by switching the arthroscope from anterolateral to anteromedial portal.

\section{Tibial AM \& PL tunnel preparation}

a. The tibial guide pin was inserted using a normal tibial guide tip aimer through the anterior part of ACL footprint

b. With the guide pin in place the same tibial aimer was used to pass another guide pin in the posterior part of the ACL footprint.

c. Two leading sutures were passed through the two femoral tunnels.

d. The suture in the AM femoral tunnel was pulled out through the AM tibial tunnel

e. The leading suture in the PL femoral tunnel was pulled out into the PL tibial tunnel.

f. Care was taken that the PL leading suture remains posterior to the AM leading suture.

g. The PL bundle was negotiated first through the tibial and femoral tunnels followed by the AM bundle.

\section{Tensioning \& fixation}

i. The graft loops were secured on the femoral side with endobutton CL or endobutton with mersiliene tape loop and on the tibial side with bio interference screws.

ii. The AM bundle is isometric and the PL bundle is anisometric.

iii. Therefore the PL bundle is secured on the tibial side first keeping the knee in $10^{\circ}$ flexion using bioabsorbable interference screw.

iv. The $\mathrm{AM}$ bundle is secured later with the knee in $30^{\circ}$ flexion.

\section{Postoperative Rehabilitation Protocol (Figure 12)}

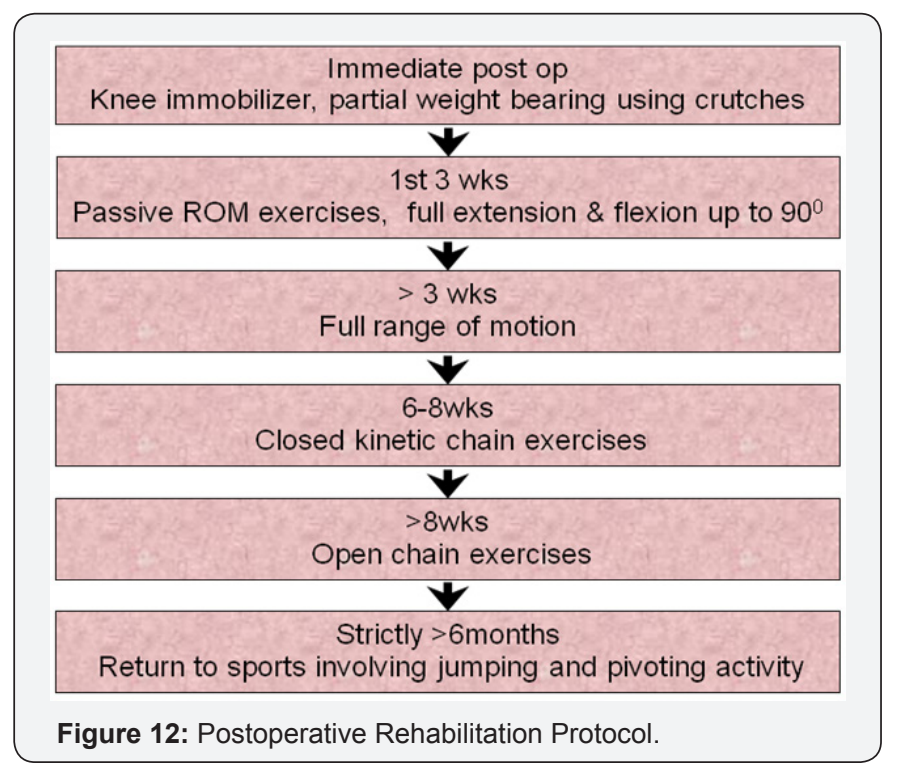

\section{Clinical assessment}

Table 2: Preoperative findings on physical examination.

\begin{tabular}{|c|c|c|c|c|}
\hline Grade & $\mathbf{0}$ & $\mathbf{1}$ & $\mathbf{2}$ & $\mathbf{3}$ \\
\hline \multicolumn{5}{|c|}{ Anterior drawer test } \\
\hline OTLP (n=18) & 0 & 0 & 11 & 7 \\
\hline SB (n=20) & 0 & 1 & 13 & 6 \\
\hline DB (n=20) & 0 & 0 & 12 & 8 \\
\hline \multicolumn{5}{|c|}{ Lachman's test } \\
\hline OTLP (n=18) & 0 & 1 & 10 & 7 \\
\hline SB (n=20) & 0 & 0 & 14 & 6 \\
\hline DB (n=20) & 0 & 0 & 13 & 7 \\
\hline
\end{tabular}




\section{Orthopedics and Rheumatology Open Access Journal (OROAJ)}

a. Recorded prior to surgery and at 1-year follow up.

b. Ligament stability was assessed by the use of Lachmans and Anterior Drawer Test.

c. Cincinnati Knee Score was used to evaluate the functional outcome.

d. Pivot shift test was not used for clinical assessment as it is less reproducible and more subjective.

e. The Cincinnati score includes hard shifts, cuts and pivots (Tables 2 \& 3).

Table 3: Cincinnati Knee Score.

\begin{tabular}{|c|c|c|}
\hline Measure & Ability & Points \\
\hline \multirow[t]{4}{*}{ Walking } & Normal unlimited & 40 \\
\hline & Some limitations & 30 \\
\hline & Only 3-4 blocks possible & 20 \\
\hline & Less than 1 block possible & 0 \\
\hline \multirow[t]{4}{*}{ Stairs } & Normal unlimited & 40 \\
\hline & Some limitations & 30 \\
\hline & Only 11 - 30 steps possible & 20 \\
\hline & Only 1 - 10 steps possible & 0 \\
\hline \multirow[t]{4}{*}{$\begin{array}{c}\text { squatting and } \\
\text { kneeling }\end{array}$} & Normal unlimited & 40 \\
\hline & Some limitations & 30 \\
\hline & Only 6 - 10 possible & 20 \\
\hline & Only $0-5$ possible & 0 \\
\hline \multirow[t]{4}{*}{ Straight running } & Full competitive & 100 \\
\hline & Some limitations guarding & 80 \\
\hline & Half-speed definite limitations & 60 \\
\hline & Not able & 40 \\
\hline \multirow[t]{4}{*}{$\begin{array}{l}\text { Jumping and } \\
\text { landing }\end{array}$} & Full competitive & 100 \\
\hline & Some limitations guarding & 80 \\
\hline & Half-speed definite limitations & 60 \\
\hline & Not able & 40 \\
\hline \multirow[t]{4}{*}{$\begin{array}{l}\text { Hard twists cuts } \\
\text { pivots }\end{array}$} & Full competitive & 100 \\
\hline & Some limitations guarding & 80 \\
\hline & Half-speed definite limitations & 60 \\
\hline & Not able & 40 \\
\hline
\end{tabular}

\section{Cincinnati knee score}

i. Functional assessment score $=$ SUM of points for all 6 activities

ii. Interpretation:

a. Minimum score: 120

b. Maximum score: 420

iii. The goal is to have the highest possible function in each of the 6 categories.

\section{Results}

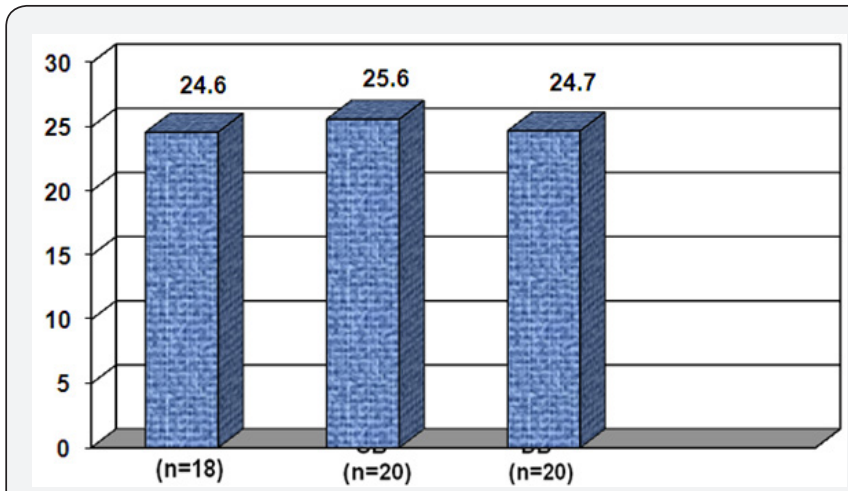

Figure 13: Mean Age at surgery in years with three different surgical techniques.

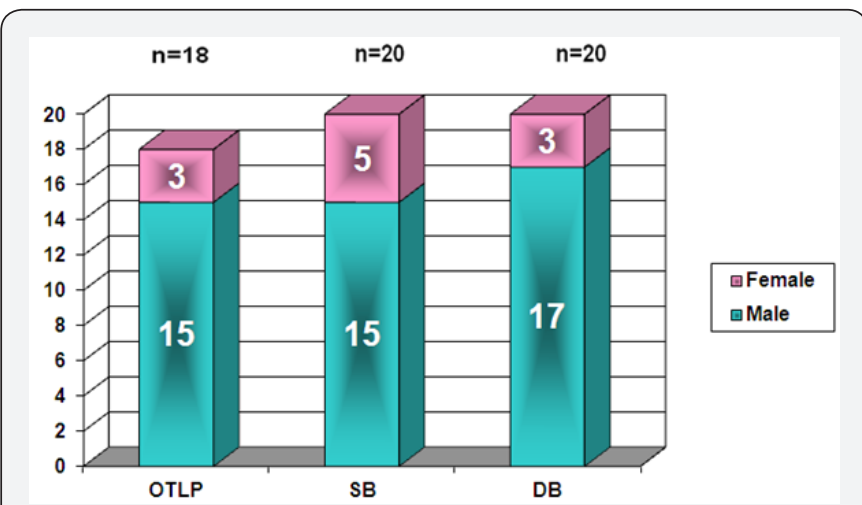

Figure 14: Male: Female ratio in patient group with different surgical techniques.

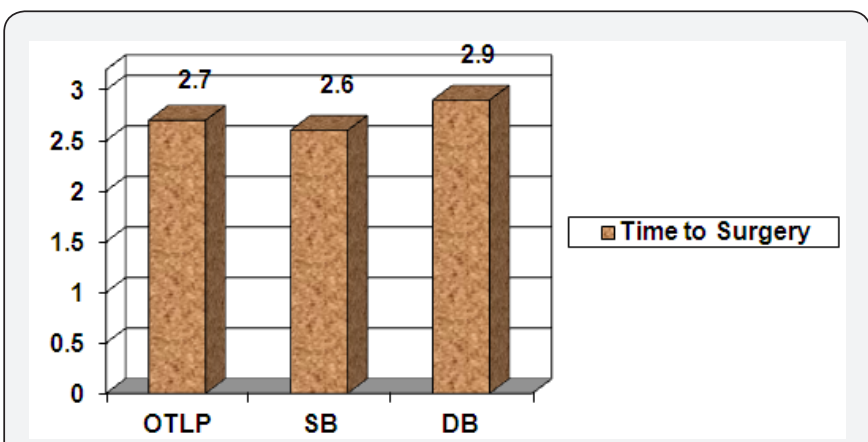

Figure 15: Mean time to surgery (in months) in patient groups with different surgical techniques. 


\section{Orthopedics and Rheumatology Open Access Journal (OROAJ)}
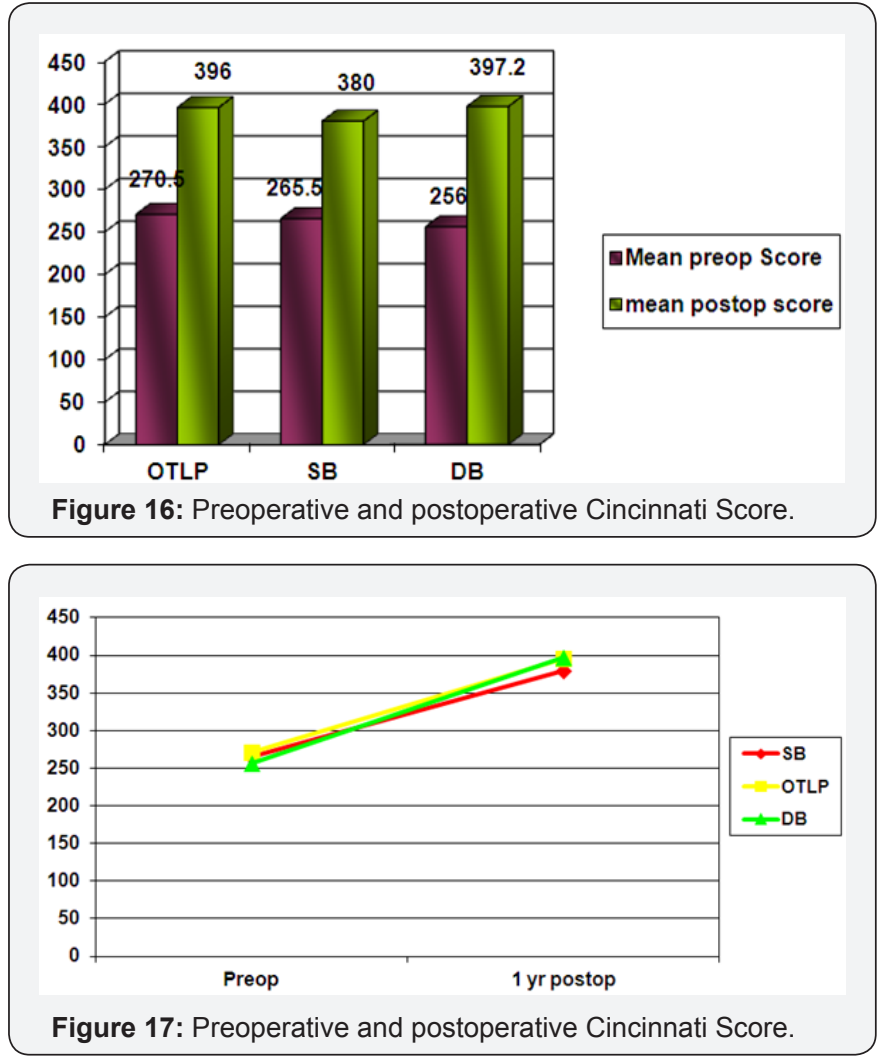

Table 4: Preoperative findings on physical examination.

\begin{tabular}{|c|c|c|c|c|}
\hline Grade & $\mathbf{0}$ & $\mathbf{1}$ & $\mathbf{2}$ & $\mathbf{3}$ \\
\hline \multicolumn{5}{|c|}{ Anterior drawer test } \\
\hline OTLP (n=18) & 0 & 0 & 11 & 7 \\
\hline SB (n=20) & 0 & 1 & 13 & 6 \\
\hline DB (n=20) & 0 & 0 & 12 & 8 \\
\hline \multicolumn{7}{|c|}{ Lachman's test } \\
\hline OTLP (n=18) & 0 & 1 & 10 & 7 \\
\hline SB (n=20) & 0 & 0 & 14 & 6 \\
\hline DB (n=20) & 0 & 0 & 13 & 7 \\
\hline
\end{tabular}

Table 5: Postoperative findings on physical examination at 1 year.

\begin{tabular}{|c|c|c|c|c|}
\hline Grade & $\mathbf{0}$ & $\mathbf{1}$ & $\mathbf{2}$ & $\mathbf{3}$ \\
\hline \multicolumn{5}{|c|}{ Anterior drawer test } \\
\hline OTLP (n=18) & 15 & 3 & 0 & 0 \\
\hline SB (n=20) & 14 & 4 & 2 & 0 \\
\hline DB (n=20) & 16 & 4 & 0 & 0 \\
\hline \multicolumn{7}{|c|}{ Lachman's test } \\
\hline OTLP (n=18) & 14 & 4 & 0 & 0 \\
\hline SB (n=20) & 15 & 3 & 2 & 0 \\
\hline DB (n=20) & 16 & 4 & 0 & 0 \\
\hline
\end{tabular}

There was no significant difference between the 3 groups with respect to age at the time of surgery, sex and time to surgery (Figures 13-17). The three surgical patient groups were compared with respect to findings of physical examination and subjective evaluation through Cincinnati Knee score (Tables 4 \& $5)$.

\section{Complications}

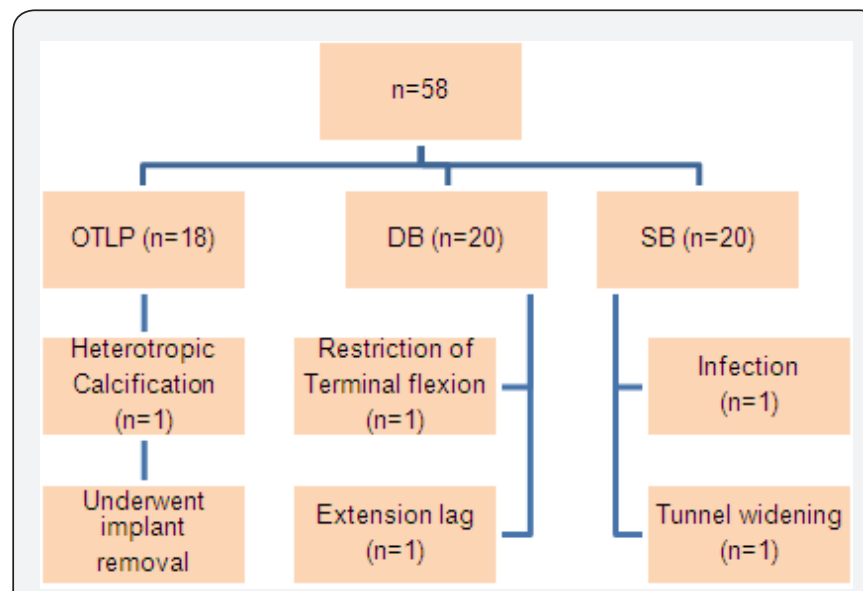

Figure 18: Complications in the three surgical groups.

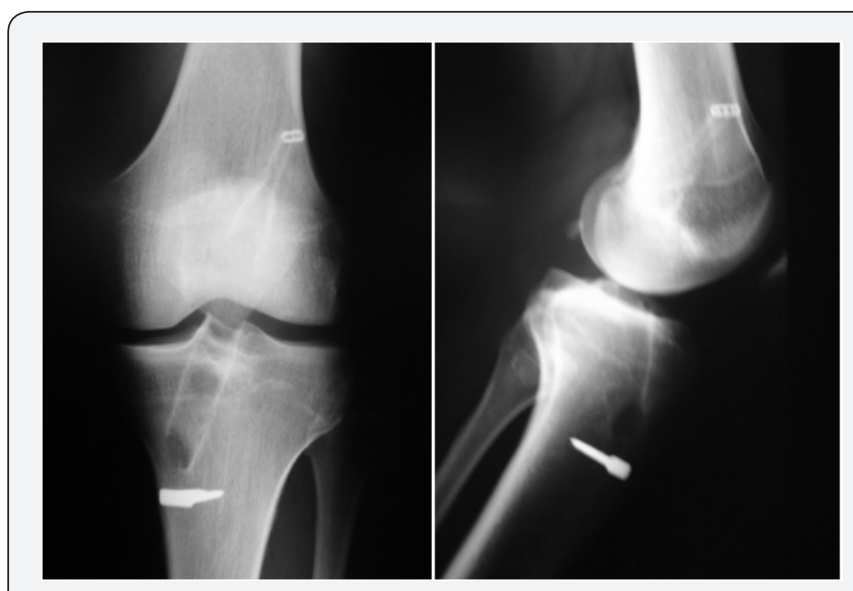

Figure 19: Tunnel widening after SB Reconstruction at $1 \mathrm{yr}$.

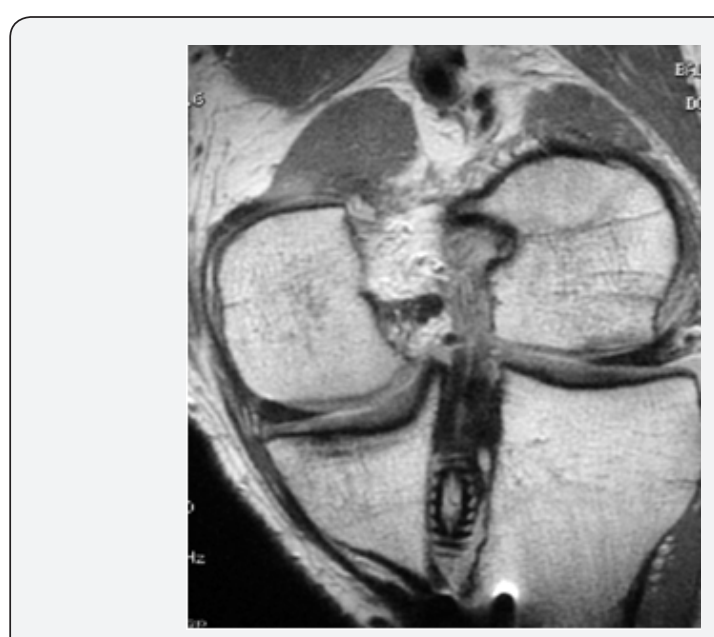

Figure 20: Tunnel widening seen on MRI. 
i. Infection ( $\mathrm{n}=1$ in SB group).

ii. Tunnel widening ( $\mathrm{n}=1$ in SB group).

iii. Heterotrophic calcification ( $\mathrm{n}=1$ in OTLP group).

iv. Restriction of terminal flexion ( $\mathrm{n}=1$ in DB group).

v. Extension lag ( $\mathrm{n}=1$ in DB group) (Figures 18-20).

\section{Discussion}

a. The overall results were comparable in all 3 groups.

b. The incidence of anteroposterior laxity was less in the DB and OTLP groups as compared to the SB group.

c. There was no incidence of kneeling pain.

d. Hypoesthesia around the graft harvest site was seen in few patients and can be attributed to the involvement of saphenous nerve.

\section{Limitations of the study}

i. The sample size was small and hence statistical analysis was difficult.

ii. The patients were not allotted to the 3 treatment groups in a randomized manner due to graft length issues and patients' financial constraints.

iii. Since we did not evaluate pivot shift test preoperatively, we were unable to determine whether rotational laxity influenced patient satisfaction with regard to surgical outcome

iv. Biomechanical evaluation like KT-2000 arthrometer is needed to further quantify the results.

\section{Conclusion}

Based on the above study analysis, it can be concluded that the overall outcome of the three surgical repair techniques for ACL reconstruction is nearly same except for fewer complications that have higher incidence with single-bundle technique. Hence, the decision of right choice is based on clinical findings, infrastructure available and financial issues.

\section{References}

1. Yasuda (2006) Clinical Evaluation of Anatomic Double-Bundle Anterior Cruciate Ligament Reconstruction Procedure Using Hamstring Tendon Grafts: Comparisons Among 3 Different Procedures. Arthroscopy 22(3): 240-251.

2. Boris A Zelle, Peter U Brucker, Matthew T Feng, Freddie H Fu (2006) Anatomical Double-Bundle Anterior Cruciate Ligament Reconstruction. Sports Med 36(2): 99-108.

3. Kurosaka M (2007) Double-bundle ACL reconstruction can improve rotational stability. Clin Orthop Relat Res 454: 100-107.

4. Noyes FR (1989) A rationale for assessing sports activity levels and limitations in knee disorders. Clin Orthopaedics and Related Research 246: 238-249.

Your next submission with Juniper Publishers will reach you the below assets

- Quality Editorial service

- Swift Peer Review

- Reprints availability

- E-prints Service

- Manuscript Podcast for convenient understanding

- Global attainment for your research

- Manuscript accessibility in different formats

( Pdf, E-pub, Full Text, Audio)

- Unceasing customer service

Track the below URL for one-step submission https://juniperpublishers.com/online-submission.php 